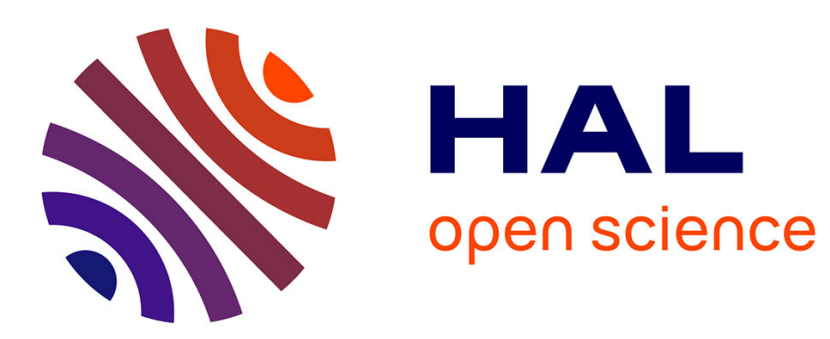

\title{
Evaluating conceptual models of landscape change
}

Lars A. Brudvig, Shawn J. Leroux, Cécile H. Albert, Emilio M. Bruna, Kendi

F. Davies, Robert M. Ewers, Douglas J. Levey, Renata Pardini, Julian Resasco

\section{To cite this version:}

Lars A. Brudvig, Shawn J. Leroux, Cécile H. Albert, Emilio M. Bruna, Kendi F. Davies, et al.. Evaluating conceptual models of landscape change. Ecography, 2017, Fragmentation 40 (1), pp.74-84. 10.1111/ecog.02543 . hal-01681550

\section{HAL Id: hal-01681550 https://hal.science/hal-01681550}

Submitted on 14 May 2018

HAL is a multi-disciplinary open access archive for the deposit and dissemination of scientific research documents, whether they are published or not. The documents may come from teaching and research institutions in France or abroad, or from public or private research centers.
L'archive ouverte pluridisciplinaire HAL, est destinée au dépôt et à la diffusion de documents scientifiques de niveau recherche, publiés ou non, émanant des établissements d'enseignement et de recherche français ou étrangers, des laboratoires publics ou privés. 


\section{Evaluating conceptual models of landscape change}

Lars A. Brudvig ${ }^{1}$, Shawn J. Leroux ${ }^{2}$, Cécile H. Albert ${ }^{3}$, Emilio M. Bruna ${ }^{4,5}$, Kendi F. Davies ${ }^{6}$, Robert M.

Ewers $^{7}$, Douglas J. Levey ${ }^{8}$, Renata Pardini ${ }^{9}$, Julian Resasco ${ }^{6}$

${ }^{1}$ Department of Plant Biology and Program in Ecology, Evolutionary Biology and Behavior, Michigan State

University, East Lansing, MI 48824 USA

${ }^{2}$ Department of Biology, Memorial University of Newfoundland, St. John's, NL, A1B3X9, Canada

${ }^{3}$ Aix Marseille Univ, Univ Avignon, CNRS, IRD, IMBE, Marseille, France

${ }^{4}$ Department of Wildlife Ecology and Conservation, University of Florida, Gainesville, FL 32611, USA

${ }^{5}$ Center for Latin American Studies, University of Florida, Gainesville, FL 32611, USA

${ }^{6}$ Department of Ecology and Evolutionary Biology, University of Colorado - Boulder, Boulder, CO 80309

USA

${ }^{7}$ Department of Life Sciences, Imperial College London, Silwood Park Campus, Buckhurst Road, Ascot,

Berkshire SL5 7PY, UK

${ }^{8}$ Division of Environmental Biology, National Science Foundation, Arlington, Virginia 22230 USA

${ }^{9}$ Department of Zoology, Institute of Biosciences, University of São Paulo, Rua do Matão, travessa 14, 101,

CEP 05508-090, São Paulo, SP, Brazil

Corresponding author: A. Brudvig, Department of Plant Biology and Program in Ecology, Evolutionary

Biology and Behavior, Michigan State University, East Lansing, MI 48824 USA. E-mail: brudvig@msu.edu

Decision date: $17-O c t-2016$

. nis article has been accepted for publication and undergone full peer review but has not been through the copyediting, typesetting, pagination and proofreading process, which may lead to differences between this version and the Version of Record. Please cite this article as doi: [10.1111/ecog.02543]. 


\section{Abstract}

A variety of landscape models are used to conceptualize and interpret human impacts on ecosystems and their biodiversity. The simplest, a 'patch-matrix' model, is rooted in Island Biogeography Theory and assumes a dichotomy between generic, easily-defined habitat patches and a surrounding matrix that is completely inhospitable. This dichotomy between patch and matrix habitats has been recently relaxed, with the 'continuum' model taking this relaxation to its extreme and logical endpoint - a species-based model with no a priori definition of habitat or matrix, but rather focusing on ecological gradients. Yet, because few empirical comparisons of these bookending models exist, we lack understanding of their relative utility or the merits of hybrid approaches that combine attributes of patch-matrix and continuum models. To guide such considerations, we first develop a decision-making framework for the application of patch-matrix, continuum, and hybrid models. The framework takes into account study objectives, attributes of the landscape, and species traits. We then evaluate this framework by empirically comparing how continuum, patchmatrix, and hybrid models explain beetle distributions across two contrasting fragmented landscapes, for species differing in trophic level and habitat specificity. Within the Hope River Forest Fragmentation Project, a system with strong landscape contrast and distinct ("hard") structural edges between forest fragments and grassland, we find broad support for hybrid models, particularly those incorporating surrounding landscape structure.

Conversely, within the Wog Wog Habitat Fragmentation Experiment, a system with weak landscape contrast and "soft" structural edges between natural and plantation forest, we find co-support for continuum and hybrid models. We find no support in either system for patch-matrix, relative to continuum and hybrid models. We conclude by considering key 
questions and areas of research for advancing the application of models to understand species responses and biodiversity patterns associated with land-use change. 


\section{Introduction}

The widespread alteration, destruction, and fragmentation of natural ecosystems for human land use represent the greatest threat to the world's biodiversity (Vitousek et al. 1997, Foley et al. 2005, Haddad et al. 2015, Newbold et al. 2015). These impacts are geographically variable and, consequently, the Earth's surface comprises landscapes ranging from highly human-modified to relatively intact (Foley et al. 2005, Ellis et al. 2010, Haddad et al. 2015) (Fig. 1). Many models have been developed to conceptualize this variety of contemporary landscapes (Fischer and Lindenmayer 2007, Didham et al. 2012). Conceptual models provide a theoretical basis to research and influence how landscapes are studied and results interpreted. Yet, no single model is likely to apply in all cases and questions remain about the appropriateness and tractability of different models for particular landscapes, study questions, and species (e.g., Dunn and Majer 2007, Lindenmayer and Fischer 2007, Lindenmayer et al. 2007, Fahrig 2013, Mendenhall et al. 2014). In this manuscript, we confront the question: "In which situations should a particular landscape model be adopted?" We do so in context of understanding the effects of habitat fragmentation on species' distributions and abundances.

The simplest landscape models are rooted in Island Biogeography Theory (MacArthur and Wilson 1967, Haila 2002), which views habitat fragments as islands embedded in a highly altered, inhospitable matrix (hereafter 'patch-matrix' models, including island and patch-corridor-matrix models; Shafer 1990, Forman 1995). In a patchmatrix model, the landscape is dichotomized into generically-defined habitat and nonhabitat (matrix) based on structural properties related to how humans perceive landscapes. Habitat patches are typically equated to relict (pre-human alteration) features (e.g., remnant 
forest) and the matrix to human-altered features (e.g., agricultural fields). Although the assumption of an inhospitable matrix has been progressively relaxed - for example by considering differential dispersal through alternative matrix types - patch-matrix models based on generically-defined high and low quality habitat types remain a common approach to conceptualizing fragmented landscapes (Kupfer et al. 2006, Fischer and Lindenmayer 2007, Laurance 2008, Collinge 2009, Pardini et al. 2010, Driscoll et al. 2013).

Whereas patch-matrix models emphasize the structural features of landscapes that are obvious to humans, 'continuum' models define habitat individually for each species across a landscape, making no assumptions about how generic, human-defined features associate to habitat (Fischer et al. 2004, Fischer and Lindenmayer 2006, Betts et al. 2014). Rather than dichotomizing habitat and matrix, continuum models treat landscapes as ensembles of gradients, resulting in habitats of varying types and qualities for a given species (Fischer and Lindenmayer 2006). Continuum models are related to the broadly used 'species distribution models', which describe species' environmental requirements as gradients (Austin 1999, Guisan and Thuiller 2005, Elith and Leathwick 2009) and can also be applied to questions about how landscape structure and change affect species distributions and abundances (Lyet et al. 2013). Continuum models emphasize speciesspecific variation in basic habitat requirements, including food availability, shelter, and preferred microclimate (Fischer and Lindenmayer 2006). This paradigm recognizes that substantial proportions of species - even those typically considered specialists - can often use matrix areas (e.g., specialists of relict habitats in human-altered landscapes; Daily et al. 2001, Daily et al. 2003). 
Finally, some models combine aspects of patch-matrix and continuum models (e.g., McIntyre and Hobbs 1999, Mendenhall et al. 2014, McCune in press); however, questions remain about when and how to develop such hybrid models (Didham et al. 2012). For example, McCune (in press) developed a hybrid model to predict occurrences of forest plant species by combining continuum-like habitat data at local extents (describing aspects of focal forest patches) with generic habitat data (forest vs. non-forested) at landscape extents. Many such approaches are possible and few have been empirically assessed. Here, we seek to advance understanding of the insights, merits, and challenges associated with these varying approaches. To do so, we consider patch-matrix and continuum models as bookends to the spectrum of landscape conceptual models, as well as hybrid approaches that incorporate both generic habitat data (forest vs. non-forested) and detailed data describing ecological gradients. Throughout, we emphasize the utility of conceptual models for guiding consideration of a question or problem (e.g., when seeking to understand the determinants of species' distribution and abundance, is it better to conceptualize landscapes based on generic, contrasting features, or as ensembles of gradients?) and for guiding empirical testing of questions (i.e., to clarify the type of data needed for statistical models of species' distributions and abundances).

This examination is important because, in addition to their conceptual basis, patchmatrix and continuum models differ in their potential advantages and disadvantages for empirical application. Reflecting its roots in Island Biogeography theory (MacArthur and Wilson 1967) and focus on species richness, patch-matrix models are simpler and might be applied to entire communities in a single study, whereas continuum models are more complicated and, with focus on individual species, must be applied to one species at a time. 
This distinction has practical implications for the type and extent of data required to apply the models. Data demands for patch-matrix models may be relatively small; for example, data on the distribution of one or more species in patches of a given habitat type coupled with maps of habitat coverage may be sufficient. In turn, important assumptions are made e.g., that humans can distinguish and define ecologically unique and relevant habitat types and that these definitions are broadly applicable across species (Fischer and Lindenmayer 2006). By comparison, data demands for continuum models are extensive - these models require data on species' distributions spanning gradients of human impacts and other environmental conditions (e.g., elevation, precipitation, edaphic conditions), including those describing habitat through availability of food, shelter, and suitable climate conditions (Fischer and Lindenmayer 2006). This represents a substantial challenge given that relevant environmental and habitat data differ among species (Didham et al. 2012). Yet, continuum models make no assumptions about how species respond to landscape gradients or alterations and thus may be more biologically accurate (Fischer and Lindenmayer 2006, Didham et al. 2012).

Patch-matrix and continuum models have differed in their frequency of application, with researchers more often drawn to the patch-matrix model. For example, a Web of Science search (conducted on 29 November 2015) for topics 'habitat fragmentation' and 'patch matrix' yielded 614 articles, including 278 published since the start of 2010. Conversely, a search for topics 'habitat fragmentation' and 'continuum' yielded roughly an order of magnitude fewer articles: 68 total and 31 published since the start of 2010. Although one might explore additional search terms, the qualitative result seems clear: a majority of research attention has focused on patch-matrix models. Similarly, a review of 
metacommunity studies found that $<1 / 3$ considered landscapes as gradients, rather than as discrete habitats of one or more types (Biswas and Wagner 2012). Moreover, although examples exist that empirically (i.e., statistically) compare species distributions within landscapes based on binary (patch-matrix) and continuous habitat definitions (e.g., Umetsu et al. 2008, Bruton et al. 2015), exceptionally few studies have attempted to fully parameterize a continuum model with covariates describing food, shelter, or other relevant, species-specific variables (though see Price et al. 2009, Betts 2014). As such, we lack the sorts of empirical comparisons of patch-matrix and continuum models that would permit evaluation of their relative merits, or those of hybrid model approaches.

Two critical questions emerge in light of the advantages and disadvantages of these alternative conceptual models: 1) Under what circumstances should one apply a simpler patch-matrix vs. a more data-intensive continuum model? And, 2) are there advantages to hybrid models that incorporate aspects of patch-matrix and continuum approaches? To address these questions, we first develop a decision-making framework to guide model selection a priori (prior to study initiation and data collection) based on study objectives and attributes of the focal landscape and species. We then test this framework by evaluating its predictions relative to how patch-matrix, continuum, and hybrid models explain species distributions of beetle assemblages in two contrasting landscapes. Finally, we propose research needed to advance the application of landscape models to understand biodiversity responses to land-use change.

\section{A framework for deciding among patch-matrix, continuum, and hybrid models}


We begin by developing a decision-making framework for considering situations under which a patch-matrix, continuum, or hybrid model might be most appropriate for evaluating the consequences of landscape change (Table 1). This framework presents three core characteristics, related to study objectives, attributes of the focal landscape and, in instances where individual species are the focus, attributes of these species. Each of these characteristics points to either a patch-matrix or continuum model. These three recommendations are then combined to reach a decision to apply a patch-matrix, continuum, or hybrid model. In instances where all three characteristics suggest either a patch-matrix or continuum model, the recommendation is that respective model. In instances where there is mixed support for patch-matrix and continuum models (e.g., two considerations suggest a patch-matrix model and one suggests a continuum model), the recommendation is a hybrid model. We note that data requirements are also an important consideration and we discuss these below, but we place decision-making emphasis on study question and characteristics of the focal landscape and species. We suggest this framework be treated as a set of hypothetical 'rules of thumb' that warrant rigorous empirical testing.

Patch-matrix and continuum models may be applied to a variety of objectives in research or conservation (Table 1). When questions pertain to a well-defined habitat type (at least from a human perspective; e.g., relict forest fragments surrounded by tilled fields) or to a community with shared habitat requirements (e.g., relict temperate forest herbs; Flinn and Vellend 2005), a patch-matrix model may be preferred due to its tractability or potential for similar performance to a continuum model. On the other hand, a continuum model may be preferred when questions pertain to a suite of non-distinct habitats (again, based on human perspective; e.g., landscapes with ecotones), to multiple species with 
varying habitat requirements, to species with poorly understood habitat affinities or to a single species - due to the model's ability to consider environmental gradients and define habitat individually for each species. In sum, the continuum model allows one to address questions pertaining to relationships between species and various biotic and abiotic gradients, whereas the patch-matrix model focuses on understanding relationships between species and dichotomous, generically-defined habitat patches.

The ability to map a patch-matrix or continuum model to a particular landscape will depend on attributes of the landscape, such as contrast among habitat types and successional dynamics (Table 1). Patch-matrix models best map onto landscapes containing few land-cover types, with hard edges and stark contrasts between cover types that can be easily classified into generic habitat types. This often applies to human-modified landscapes in which the original habitat is relatively homogeneous and has been converted to very distinct cover types (e.g. forest and pasture). Conversely, continuum models have advantages when applied to landscapes consisting of many land-cover types and weak contrasts between cover types. Finally, because species composition is affected by successional stage (time since major disturbance) (Connell and Slatyer 1977, Ewers et al. in press), a continuum model may have advantages in landscapes supporting a variety of successional stages, due to its ability to confront the resulting variation in biotic and abiotic conditions, whereas a patch-matrix model may be adequate in landscapes supporting one or few successional stages.

Characteristics of the study species will additionally influence the applicability of patch-matrix and continuum models (Table 1). In situations where focal species are specialists of an easily-defined habitat, a patch-matrix model may perform equally well to a 
continuum model and may be preferred owing to its simplicity and lesser data requirements. Conversely, a continuum model may better describe species distributions, relative to a patch-matrix model, when studying generalist species or species that use multiple habitats, for instance due to daily or seasonal variation in foraging. These sorts of considerations may be informed by natural history knowledge; however, in cases where such knowledge is not available, species traits may provide insights. For example, species at the top of food webs typically require large foraging areas and consequently are often absent from small fragments or require a variety of habitat types that cannot be summarized by simple structural attributes (e.g., Gilbert et al. 1998, Holt 1997, Holyoak 2000, Terborgh et al. 2001). This suggests that trophic level may be an informative trait and, perhaps, a patch-matrix model may be adequate for top trophic levels, particularly when individuals require large tracts of contiguous habitat, whereas a continuum model may perform better for establishing the more variable responses of lower trophic levels to landscape changes. Traits associated with mobility (in animals) or disperser and pollinator type (in plants) may also be relevant. Mobile taxa that range widely and use multiple land cover types across a landscape may be best captured by a continuum model, whereas a patch-matrix model may be suitable for less mobile taxa. We recognize the potential for conflicting predictions (e.g., plants are both low trophic level and immobile for large parts of their life cycle); empirical tests are needed to critically evaluate these initial guidelines.

In each of these cases, an important practical consideration is the data required to parameterize models (Table 1). Because it assumes an inhospitable matrix, the simplest patch-matrix model requires only data describing occupancy or abundance for one or more species across a set of habitat patches within a landscape, along with information about 
those patches (e.g., GIS data to derive patch area). Addressing questions with a continuum model will require data to describe patterns of species occupancy/abundance, and relevant covariates that rarely can be obtained from a map but rather have to be measured in the field. In short, a patch-matrix model may include a large number of variables, which are relatively easily obtained (e.g., GIS-derived) and can be applied to all species, whereas a continuum model may include relatively few field-collected variables, which are more difficult to obtain and can be applied to only one or a few species (though we note that continuous GIS data, such as for elevation, may also be available). Continuum models are thus more data intensive than patch-matrix models, indicating the importance of careful consideration of a feasible sampling design (Albert et al. 2010). In instances where data are lacking and financial or other constraints preclude their collection, a patch-matrix model may be the only option; in such cases, study objectives should be formulated carefully to match the model's assumptions.

\section{Implementing and testing the decision-making framework: Empirical consideration of patch-matrix, continuum, and hybrid models}

We next apply and thereby evaluate the decision-making framework to determine which model is best suited to explain local abundance of a given species across a landscape - a common consideration in fragmentation studies. Whereas the patch-matrix and continuum models were originally designed to model community and species responses, respectively, both approaches can be applied to communities and species-responses (Leroux et al. in press). Indeed, as Leroux et al. (in press) argue, the comparison and potential integration of disparate conceptual models requires that such models be applied to 
common currencies (i.e., richness or species). Here, we focus on species-level predictions arising from patch-matrix and continuum model concepts. To do so, we compare evidence in support of the different conceptual models by mapping our conceptual models to statistical models to explain various beetle species across two structurally-distinct fragmented landscapes. The Hope River Forest Fragmentation Project (HRFFP; New Zealand, Ewers et al. 2007) is an observational study of forest and open grassland, providing strong contrasts with structurally-hard edges between habitat types. Conversely, the Wog Wog Habitat Fragmentation Experiment (Australia, Margules 1993) consists of embedded relict forest within plantation forest, providing low contrasts with structurallysoft edges between habitat types. For each study, we constructed statistical models of beetle species abundances across sampling locations as a function of generic habitat type alone (patch-matrix model), continuous environmental variables (continuum model), and a combination of generic habitat type and environmental variables (hybrid model). Based on the focal study question - what determines local abundance of a species across a landscape? - and characteristics of these two landscapes, we expected that patch-matrix and hybrid models would best predict species abundances in the high contrast HRFFP landscape, whereas hybrid and continuum models would best predict species abundances in the low contrast Wog Wog landscape (Table 2).

\section{Hope River Forest Fragmentation Project}

In the HRFFP, beetles were sampled from November 2000 - February 2001 within 15 southern beech forest fragments varying in area ( 0.01 to $>1,000,000$ ha) and the surrounding grassland (previously cleared forest below 1,300 meters above sea level and 
naturally occurring alpine grasslands above), in South Island, New Zealand (Ewers et al. 2007). At each fragment, up to 11 sampling plots stratified by their proximity to the fragment edge were established inside and outside the forest fragment, including one location at the edge of each fragment. The number of sampling plots per site depended on the size of the forest fragment, with more plots located in larger forest fragments. In addition to the 15 paired forest fragment/edge/grassland sites, there was one additional large forest fragment site and one additional large grassland site both containing 21 sampling plots. From the total of 893 species collected, we selected six broadly-distributed species (for analytical tractability and feasibility) spanning trophic level and restrictedness to forest or grassland (Ewers et al. 2007): a forest-specialist carnivore, a forest-specialist herbivore, a grassland-specialist carnivore, a grassland-specialist herbivore, a generalist (found in forest and grassland) carnivore, and a generalist herbivore (Appendix A). The original dataset included 79 covariates obtained for each of the 233 sampling locations; Ewers et al. (2007) used forward selection within a partial redundancy analysis to reduce the number of covariates to the 26 variables that explained a significant portion of the variance in beetle species composition among sites. We further reduced this set by retaining only the variables that explained $>1 \%$ of the variation in beetle species composition among sites when they were sequentially added to the model and for which there was not significant colinearity with other model variables (i.e., variance inflation factor < 3).

We then constructed separate generalized linear mixed models (GLMM) with zeroinflated Poisson distributions for each species, predicting number of individuals at each sampling location, based on the location's generic habitat type (forest; grassland; edge), patch variables (an integrated variable for patch area and distance to the edge), site 
variables (tree species richness; canopy height; two principle component axes describing ground cover; average daily temperature range; average daily relative humidity difference, relative to an open-canopy reference), and landscape variables (distance to continuous forest; number of forest fragments within $8192 \mathrm{~m}$; and a forest connectivity index with radius 512m) (see Ewers et al. 2007 for descriptions of covariates).

To assess the fit of patch-matrix, continuum and hybrid models in this landscape, we built six competing models with different sets of variables: i) a patch-matrix model that included the generic habitat type, patch variables, and landscape variables, ii) a patchmatrix model that included generic habitat type and patch variables, but no landscape variables, iii) a continuum model that included site variables, iv) a hybrid model that included site and patch variables, v) a hybrid model that included site and landscape variables, and vi) a hybrid model that included site, patch, and landscape variables. All models included the number of sampling days to account for variation among sampling locations. In addition, we included an intercept-only null model. All models also included two random effects; site which accounts for the pairing of forest fragment/matrix at each site and plot replicate which accounts for the multiple plots per treatment. We compared among models for each species using model selection and considered models within four AICc points of the top model as having support (model support was identical for $\triangle \mathrm{AICc}$ of 2 or 4 , or for cumulative AICc weights of 0.95 ; Appendix A). This model selection approach accounts for the variation in number of parameters among the models we compare by considering both model fit and the number of parameters.

Some of the mixed effects zero inflated Poisson models for the Grassland-specialist carnivore ( $\mathrm{n}=2$ models), the Generalist herbivore ( $\mathrm{n}=5$ models) and Forest-specialist 
herbivore $(\mathrm{n}=2)$ did not converge. In these instances, we fit reduced (dropped plot as random effect but retained site as random effect) mixed effects zero inflated Poisson models on average values of each covariate and the sum of species abundances per treatment block (Bolker 2015). For the Grassland-specialist carnivore and the Generalist herbivore, the top-ranked models for the full and reduced mixed models were identical. For the Forest-specialist herbivore, a continuum model was top ranked in the full (Continuum Patch) and reduced (Continuum Landscape) mixed model analysis. The results for the reduced mixed models therefore support our full mixed model analysis.

Based on our decision-making framework (Table 1) and the high contrast HRFFP landscape with hard edges, we expected a patch-matrix model to best predict abundances of specialist carnivores and a hybrid model to best predict abundances of herbivores and generalist species (with the null model also potentially a strong predictor of generalists). We note that our framework presents conflicting predictions for habitat generalist carnivores and habitat specialist herbivores; however, we predicted hybrid models would be supported for these species given the mixed expectations, based on trophic level and habitat specificity.

In the HRFFP, we found support for continuum and hybrid models, with the most frequent support for hybrid models, and no support for patch matrix models (Table 2, Appendix A). Counter to our expectations, hybrid (and not patch-matrix) models most parsimoniously explained variation in the abundance of forest- and grassland-specialist carnivores across this landscape. Matching our expectations, hybrid (but not patch-matrix) models were among the most parsimonious models for abundance of lower trophic level herbivores and the generalist carnivores; there was one instance where the continuum and 
hybrid models received support. This included one species with support for the continuum model (generalist carnivore), five with support for a hybrid model including landscape attributes (forest-specialist carnivore, grassland-specialist carnivore, generalist carnivore, grassland-specialist herbivore, generalist herbivore), two with support for a hybrid model including patch attributes (generalist carnivore, forest-specialist herbivore), and two with support for a hybrid model including both landscape and patch attributes (generalist carnivore, grassland-specialist herbivore).

\section{Wog Wog Habitat Fragmentation Experiment}

The Wog Wog Habitat Fragmentation Experiment is located in southeastern New South Wales, Australia in native Eucalyptus forest (Fig. 1; Margules 1993; Davies and Margules 1998, Davies et al. 2000). The experiment consists of three patch sizes (0.25 ha, 0.875 ha, and 3.062 ha). Four replicates of each size (twelve patches total) became habitat fragments when the surrounding Eucalyptus forest was cleared in 1987 and planted with Pinus radiata, for plantation timber. Two replicates of each patch size (six total) remained in uncleared continuous forest, and serve as unfragmented controls. Within patches, multiple sampling plots were established, stratified by their proximity to the patch edge. Following clearing, an additional 44 sampling plots, grouped into clusters mimicking fragmented and continuous patches, were established in the cleared forest between the forest fragments, resulting in 188 total sampling plots. Sampling of all plots took place over nine, seven-day periods, in spring, summer and autumn, 2009-2013. By this time, the formerly cleared forest was mature pine plantation, providing little structural contrast to the Eucalyptus forest. Environmental covariates were measured at all 188 sample plots, 
including ground cover, quantity of fallen wood in different size classes, soil properties, temperature, and light. We selected six of 555 species captured that were sufficiently abundant for statistical analysis and that spanned variation in trophic level and habitat specificity: two carnivores and an herbivore that were specialists of Eucalyptus forest and a carnivore, xylum feeder, and detritus feeder that were generalists, occurring in both Eucalyptus forest and pine plantation (Appendix B).

We then constructed GLMM's with Poisson distributions to predict counts of individuals for each species, at each sampling plot. Similar to the HRFFP data analysis, we fit three models for each species: i) a patch-matrix model that included the generic habitat type (Eucalyptus fragment, continuous Eucalyptus forest, or pine plantation), ii) a continuum model that contained only environmental variables collected in Eucalyptus forest and pine plantation, and iii) a hybrid model that contained both generic habitat type and environmental variables. Unlike in the HRFFP analyses, landscape variables were not included in the Wog Wog analyses because the Wog Wog experiment occurs within a single landscape, presenting little variation in surrounding landscape composition among plots. The patch-matrix model included generic habitat type as a fixed effect and two random effects: one describing the patch replicate and one describing the sampling patch (to account for the fact that sampling plots are nested within patches, which are nested within patch replicates). For the continuum and hybrid models, we individually screened each environmental variable for significance. We then fit a full model of all significant environmental variables as fixed effects, plus replicate and patch as random effects. The environmental variables we considered were: soil $\mathrm{pH}$, soil wetness, soil organic carbon, dominant wood diameter, dominant wood type (rotting, hard), dominant ground cover, 
mean litter depth, percent canopy cover, and mean temperature. The continuum model for each species included significant environmental variables as fixed effects, plus replicate and patch as random effects. Because different environmental variables were important for each species, each model was slightly different. The hybrid model included significant environmental variables and generic habitat type as fixed effects, plus replicate and patch as random effects. In addition, we included an intercept-only null model. We then compared among models for each species using model selection and considered models within four AICc points of the top model as having support (model support was very similar for $\triangle \mathrm{AICc}$ of 2 or 4, or for cumulative AICc weights of 0.95; Appendix B).

Based on our decision-making framework (Table 1) and the low contrast Wog Wog landscape with soft edges, we expected a continuum model to best predict abundances of the habitat generalist xylem feeder and detritivore and for a hybrid model to best predict abundances of the habitat specialists and carnivores (with the null model also potentially a strong predictor of generalists). We again note that our framework presents conflicting predictions for habitat generalist carnivores and habitat specialist herbivores; however, we again predict hybrid models will be supported for these species given the mixed expectations, based on trophic level and habitat specificity.

At Wog Wog, we found support for continuum and hybrid models; both were supported across all species except one Eucalyptus forest-specialist carnivore, for which only the continuum model was supported (Table 2, Appendix B). These findings broadly matched our predictions, with the expected hybrid or continuum model among the best model for all species; however, we also note the broad dual support for hybrid and continuum models, which was surprising to us. Also matching our predictions, the patch- 
matrix model was not supported for any species, which may reflect the current similarity in habitat structure between the Eucalyptus forest and pine plantation. We note that hybrid models were supported for species that were Eucalyptus forest-specialists, regardless of trophic position (herbivores vs. carnivores).

\section{Synthesis of empirical model tests}

These empirical model tests partly, but not fully, supported our conceptual model decision making framework (Table 2). Within the HRFFP, where forest and grassland form a landscape with hard edges and strong contrasts between habitats, hybrid models were largely supported for herbivores and habitat generalists (as we predicted), but patch-matrix models were not supported for habitat specialist carnivores (counter to our predictions). Conversely, within the Wog Wog Habitat Fragmentation Experiment, where relict and plantation forests form a landscape with softer edges and weaker contrasts among habitats, we again found no support for patch-matrix models - this time as we predicted; this was true even for species previously identified as relict forest specialists. Rather, continuum and hybrid models were typically co-supported for the six Wog Wog species. This was again largely as we predicted, but the co-support was surprising to us. In sum, our empirical findings are largely in line with our decision-making framework predictions, though we must be careful not to over-generalize these results, given our modest sampling of landscapes $(n=2)$ and species $(n=12)$. Certainly, more extensive tests of the hypotheses within our decision-making framework are warranted (Table 1).

A take-home lesson of the case studies is the utility of hybrid models; for every species, a hybrid model - one that incorporated generic habitat types at either the patch or 
the landscape scale, together with environmental variables - was among the best models for predicting variation in beetle abundance across landscapes. This has at least two nonmutually exclusive explanations. First, despite our extensive covariate data, it is likely that some important covariates remained unmeasured, including those correlated with our designated patches and matrix. Because fragmentation impacts may be indirect and operate through alterations to ecological processes that in turn impact the distribution of individuals and species (Didham et al. 2012), the coupling of patch-matrix designation with covariates may have provided additional predictive power by accounting for additional unmeasured local-scale gradients. Second, in five cases with HRFFP data, a hybrid model was supported that included landscape-scale variables, illustrating an important consideration of spatial scale (note that Wog Wog did not incorporate analogous landscape data). As originally envisioned, the continuum model largely deals with local-scale habitat considerations (food, shelter, climate; Fischer and Lindenmayer 2006). These factors may be affected by large-scale processes, but in most cases probably reflect the sorts of localscale processes accounted for by the many environmental covariates in our models. Thus, our hybrid models likely benefited from better consideration of important aspects of landscape structure, such as considerations of connectivity, not accounted for by local-scale environmental variables alone.

Together, these results illustrate several important points regarding the empirical application of patch-matrix, continuum, and hybrid models. First, although data intensive, full adoption of continuum models and their hybrid variants is feasible. To our knowledge, our two case studies are among the first to parameterize continuum models with relevant covariates describing habitat for individual species (but see Price et al. 2009, Betts et al. 
2014). Second, although we predicted it would perform best in some cases, we surprisingly found no support for the patch-matrix model. Rather, the more complex continuum model and, in particular, hybrid models can better predict species abundances than can patchmatrix models. A natural extension of our work would consider how patch-matrix, continuum, and hybrid models predict community-level patterns, through response variables such as richness or community composition (Collins et al in press), or through the stacking of individual species predictions (Leroux et al. in press). Finally, the details of when particular models perform best may be contingent on attributes of the landscape and focal species, often as we suspected in our decision-making framework (Table 1).

\section{Perspectives for advancing the application of landscape models to understand biodiversity responses to land-use change}

A more complete vetting of patch-matrix, continuum, and hybrid models will require new research. What might this entail? First, there needs to be more focus on sampling species and covariates describing habitat in areas traditionally considered 'matrix'. This became readily apparent as we sought datasets for use in our case studies. Despite the large number of fragmentation studies (see recent reviews in Pfeifer et al. 2014, Haddad et al. 2015), few datasets available to us included sampling both in and outside of relict habitat patches (but see Bruna and Kress 2002, Bruna and Nogueira-Ribeiro 2005, Brudvig et al. 2009), and virtually none included environmental data describing habitat for species in both relict patches and surrounding modified areas. Such focus likely stems from the Island Biogeography Theory-based origins of habitat fragmentation research (Haila 2002). Both of our case studies call this focus into question, as simple patch-matrix models were 
never supported over continuum or hybrid models. Clearly, if we are to compare among landscape models, the requisite data must be collected.

New research to evaluate conceptual landscape models might take place in existing 'naturally-' or experimentally-fragmented landscapes. In naturally-fragmented landscapes, a first step could be to identify the relationships between species distributions, environmental conditions, and land-cover types through systematic (e.g., along grids) or random-location sampling. Subsequent sampling might then focus on areas (e.g., land cover types) that warrant specific attention. Though designed to test a patch-matrix conceptual model, fragmentation experiments, like the Wog Wog habitat fragmentation experiment and others (Debinski and Holt 2000, Haddad 2015), are also useful for evaluating continuum and hybrid models; we did so through sampling within and outside of experimental habitat patches for both species and environmental data. With the exception of the Biological Dynamics of Forest Fragments Project, where fragments are inadvertently surrounded by three different matrix types (Mesquita 2001), experimentally-fragmented landscapes are typically designed with two strongly contrasting land covers (e.g., relict and cleared forest; Debinski and Holt 2000) and may present less variation in habitat condition, relative to many natural landscapes containing a variety of ecotones in addition to distinct land cover types and edges. Yet, important insights can be gained by considering how species organize along pre-existing and experimental gradients (e.g., Alexander et al. 2012), as well as through the changes that occur over time with long-running fragmentation experiments (Haddad et al. 2015, Collins et al. in press, Ewers et al. in press). For example, pine plantation has grown around Eucalyptus fragments at Wog Wog for over 30 years and, while a patch-matrix model was useful for interpreting beetle abundances in Wog Wog 
early in the experiment (Davies and Margules 1998, Davies et al. 2000), we show greater utility of continuum and hybrid models following plantation growth (but also note that past efforts did not compare among patch-matrix, continuum, and hybrid models, nor were requisite environmental data collected until recently). In sum, as we demonstrated, existing naturally- and experimentally-fragmented landscapes may be harnessed to compare patchmatrix, continuum and hybrid models.

Ultimately, however, the gold standard for comparing various landscape models will be experiments designed explicitly for that purpose. To date, the Stability of Altered Forest Ecosystems Project, which embeds relict forest fragments of varying sizes within land covers of differing types, comes the closest to such an effort (Ewers et al. 2011). However, for the purpose of comparing landscape models and their underlying principles and assumptions, we suggest a variation on the classic habitat fragmentation experiment one based on a before-after-control-impact design (Fig. 2). A long-intact landscape (or, ideally, set of landscapes) might be sampled extensively (e.g., across random or stratified locations) for one or more species' abundances and relevant environmental data describing habitat. Then, an experimental fragmentation of this landscape might occur - for example, an expansive, intact forest might be fragmented into patches by clearing, or habitat patches might be created within a modified landscape through ecological restoration. At that point, data collection would continue to describe species' abundances and environmental conditions across areas that have become fragments and the surrounding altered areas, along with unaltered control areas. Finally, data collection might continue over time to describe relationships between species distributions and habitat variables, as the landscape recovers and habitat covariates in relict patches and formerly cleared areas (presumably) 
converge over time. Through the comparison of species abundances and habitat covariates before and after treatment imposition, and across altered and unaltered areas, patch-matrix, continuum, and hybrid models could be compared directly. Moreover, data collected from such experiments could be used to parameterize dynamic landscape simulation models, such as Landis II (Scheller et al. 2007) and CONSERV (Leroux et al. 2007), for predicting changes in biodiversity under various landscape and global change scenarios.

Looking beyond our two case studies, how do patch-matrix, continuum, and hybrid models map to questions at the forefront of landscape ecology? We consider three such areas of research; outlined by Haddad et al.'s (2015) recent habitat fragmentation synthesis: 1) synergies between fragmentation and global changes, 2) eco-evolutionary responses of species to fragmentation, and 3) impacts of fragmentation on ecosystem services. Of these, a continuum or hybrid approach might apply strongly to the first two questions, with their foci on complex gradients and species-level responses to landscape change, respectively. A hybrid approach might be particularly beneficial to understanding the interface between land use and global change because of its ability to consider how global climatic changes impact existing well-defined fragments or protected areas. A continuum or hybrid approach might also be most applicable to eco-evolutionary studies because of the potential for incorporating variation in ecologically- or evolutionarily-selective factors (Legrand et al. in press). Consideration of how fragmentation affects ecosystem services might benefit from different approaches, depending on the service of interest. For example, hybrid approaches may best assist understanding of services such as crop pollination and pest regulation, which are produced through spillover effects between natural and agricultural areas (Rand et al. 2006) and are likely affected by numerous landscape gradients such as those 
influencing crop growth, foraging success, arthropod dispersal, and other factors. In such cases, given the role of landscape structure in determining ecosystem services in fragmented landscapes (e.g., Mitchell et al. 2014), we suggest a hybrid model that considers landscape context (Table 2, Appendix A). Conversely, a patch-matrix model might be useful for considering timber provision across an agricultural landscape, where natural habitats (forests) provide the majority of this service. Regardless of conceptual underpinnings, landscape ecosystem service models should additionally incorporate considerations of how humans perceive and interact with landscapes to generate services. Landscape ecology has a long history of providing guidance on how to manage exploited landscapes to minimize negative impacts on native species and ecosystems. For example, forest harvesting practices in parts of the boreal forest in Canada are informed by studies of forest fragmentation effects on boreal forest species and ecosystems (Schmiegelow and Mönkkönen 2002) and there is longstanding focus on establishing large, connected protected areas in fragmented landscapes (see Noss and Cooperrider 1994). However, what is the best strategy for long-term persistence of biodiversity in intact landscapes? As human-oriented land-use increasingly threatens remaining wilderness areas (sensu Mittermeier et al. 2003), the time for proactive conservation of such areas is limited. Consequently, continuum or hybrid models may be most suitable for prioritizing conservation in the World's remaining intact landscapes as they better capture the natural environmental gradients that may characterize these areas. To inform conservation, experiments and models must test how different preservation patterns (i.e., the inverse of fragmentation patterns) influence the long-term sustainability of biodiversity. In turn, work is needed to understand how the results of patch-matrix, continuum, and hybrid models 
may be best translated into conservation policy. For example, do the insights provided by continuum and hybrid models result in the need for different policy decisions, relative to those resulting from patch-matrix models, and do the consequences of such policy justify the added data expenses and complexities of continuum and hybrid models?

Finally, we look to the future of applying landscape models. Our decision-making framework points toward a prospective future, whereby decisions over which landscape model to apply may be made a priori, directing data collection from the onset of a project. To realize this future, however, additional retrospective tests will be necessary to refine the decision-making framework that we have suggested (Table 1). With this, the challenge will be data demands. Our retrospective tests of landscape models were unusual in the quantity of data we were able to bring to bear, yet these large datasets were necessary to directly compare patch-matrix, continuum, and hybrid models.

\section{Conclusions}

Effective application of landscape models is critical to interpreting human impacts on ecosystems and biodiversity, and to the conservation of heterogeneous landscapes. Our work illustrates the potential for broad utility of hybrid models, which incorporate aspects of generically-defined habitat and gradients of environmental attributes. Such hybrid models may be particularly well suited to addressing pressing questions in conservation, land-use, and climate change and they hold the potential to work across landscapes ranging from the most heavily altered to the most intact.

\section{Acknowledgments}

'This article is protected by copyright. All rights reserved.' 
We thank Nick Haddad, Bob Holt, and Rob Fletcher, for coordinating and editing this Special Issue and Raphael Didham for contributing data from the Hope River Forest Fragmentation Project. LB (DEB-1354085), KD (DEB-0841892, DEB-1350872), JR (Postdoctoral Research Fellowship 1309192), and DL are supported by the National Science Foundation (NSF); views expressed in this publication do not necessarily represent those of NSF. RE is supported by European Research Council Project number 281986. SL is supported by Natural Sciences and Engineering Council of Canada - Discovery Grant \#RGPIN 435372-2013. This work contributes to the Labex OT-Med ( ${ }^{\circ}$ ANR-11-LABX0061) funded by the French government through the A*MIDEX project ( $\mathrm{n}^{\circ}$ ANR-11IDEX-0001-02). 


\section{References}

Albert, C. H. et al. 2010. Sampling in ecology and evolution - bridging the gap between theory and practice. - Ecography 33: 1028-1037.

Alexander, H. M. et al. 2001. Metapopulations and metacommunities: combining spatial and temporal perspectives in plant ecology. - J. Ecol. 100: 88-103

Austin, M. P. 1999. A silent clash of paradigms: some inconsistencies in community ecology. - Oikos 86: 170-178.

Betts, M. G. et al. 2014. A species-centered approach for uncovering generalities in organism responses to habitat loss and fragmentation. - Ecography 37: 517-527.

Biswad, S. R. and Wagner H. M. 2012. Landscape contrast: a solution to hidden assumptions in the metacommunity concept? - Landscape Ecol. 27: 621-631.

Bolker, B. 2015. Linear and generalized linear mixed models. - In Fox, G. A. et al. (eds.), Ecological Statistics: Contemporary theory and application. Oxford Univ. Press, pp.309- 333.

Brudvig, L. A. et al. 2009. Landscape connectivity promotes plant biodiversity spillover into non-target habitats. - P. Natl. Acad. Sci. USA 106: 9328-9332.

Bruna, E. M. and W. J. Kress. 2002. Habitat fragmentation and the demographic structure of an Amazonian understory herb (Heliconia acuminata). - Conserv. Biol. 16: 1256-1266.

Bruna, E. M. and M. B. Nogueira-Ribeiro. 2005. Regeneration and population structure of Heliconia acuminata in Amazonian secondary forests with contrasting land-use histories. - J. Trop. Ecol. 21: 127-131. 
Bruton, M. J. et al. 2015. Testing the relevance of binary, mosaic and continuous landscape conceptualisations to reptile in regenerating dryland landscapes. - Landscape Ecol.

30: $\quad 715-728$.

Collinge, S. K. 2009. Ecology of fragmented landscapes. - Johns Hopkins University Press.

Connell, J. H. and Slatyer, R. O. 1977. Mechanisms of succession in natural communities

and their role in community stability and organization. - Am. Nat. 111: 1119-1144.

Daily, G. C. et al. 2001. Countryside biogeography: Use of human-dominated habitats by the avifauna of southern Costa Rica. - Ecol. Appl. 11: 1-13.

Daily, G. C. et al. 2003. Countryside biogeography of neotropical mammals: Conservation opportunities in agricultural landscapes of Costa Rica. - Conserv. Biol. 17: 18141826.

Davies, K. F. and Margules, C. R. 1998. Effects of habitat fragmentation on carabid beetles: $\quad$ Experimental evidence. - J. Anim. Ecol. 67: 460-471.

Davies, K. F. et al. 2000. Which traits of species predict population declines in experimental forest fragments? - Ecology 81: 1450-1461.

Debinski, D. M. and Holt, R. D. 2000. A survey and overview of habitat fragmentation experiments. - Conserv. Biol. 14: 342-355.

Didham, R. K. et al. 2012. Rethinking the conceptual foundations of habitat fragmentation research. - Oikos 121: 161-170.

Dunn, A. G. and Majer, J. D. 2007. In response to the continuum model for fauna research:

a hierarchical, patch-based model of spatial landscape patterns. - Oikos 116: 14131418. 
Elith, J. and Leathwick, J. R. 2009. Species distribution models: Ecological explanation and prediction across space and time. - Annu. Rev. Ecol. Evol. S. 40: 677-697.

Ellis, E. C. et al. 2010. Anthropogenic transformation of the biomes, 1700 to 2000. - Global Ecol. Biogeogr. 19: 589-606.

Ewers, R. M. et al. 2007. Synergistic interactions between edge and area effects in a heavily fragmented landscape. - Ecology 88: 96-106.

Ewers, R. M. et al. In press. Predicted trajectories of tree community change in Amazonian rainforest fragments. Ecography.

Ewers, R. M. et al. 2011. A large-scale forest fragmentation experiment: the Stability of Altered Forest Ecosystems Project. - Philos. T. Roy. Soc. B 366: 3292-3302. Fahrig, L. 2013. Rethinking patch size and fragmentation effects. - J. Biogeogr. 40: 16491663.

Fahrig, L. et al. 2011. Functional landscape heterogeneity and animal biodiversity in agricultural landscapes. - Ecol. Let. 14: 101-112.

Fischer, J. et al. 2004. Appreciating ecological complexity: Habitat contours as a conceptual landscape model. - Conserv. Biol. 18: 1245-1253.

Fischer, J. and Lindenmayer, D. B. 2006. Beyond fragmentation: the continuum model for fauna research and conservation in human-modified landscapes. - Oikos 112: 473-480. Fischer, J. and Lindenmayer, D. B. 2007. Landscape modification and habitat fragmentation: a synthesis. - Global Ecol. Biogeogr.16: 265-280.

Flinn, K. M. and Vellend, M. 2005. Recovery of forest plant communities in postagricultural landscapes. - Front. Ecol. Environ. 3: 243-250. 
Forman, R. T. 1995. Land mosaics: the ecology of landscapes and regions. - Cambridge University Press.

Foley, J. A. et al. 2005. Global consequences of land use. - Science 309: 570-574.

Gilbert, F. et al. 1998. Corridors maintain species richness in the fragmented landscapes of a microecosystem. - P. R. Soc. B 265: 577-582.

Guisan, A. and Thuiller, W. 2005. Predicting species distribution: offering more than simple habitat models. - Ecol. Lett. 8: 993-1009.

Haddad, N. M. et al. 2015. Habitat fragmentation and its lasting impact on Earth's ecosystems. - Science Advances 1e1500052.

Haila, Y. 2002. A conceptual genealogy of fragmentation research: from island biogeography to landscape ecology. Ecol. Appl. 12: 321-334.

Holyoak, M. 2000. Habitat subdivision causes changes in food web structure. - Ecol. Lett. 3: $\quad 509-515$.

Holt, R. D. 1997. From metapopulation dynamics to community structure: some consequences of spatial heterogeneity. - In: Hanski, I. A. and Gilpin, M. E. (ed.), Metapopulation Biology: Ecology, Genetics, and Evolution. Academic Press, pp. 149164.

Kupfer, J. A. et al. 2006. Not seeing the ocean for the islands: the mediating influence of matrix-based processes of forest fragmentation effects. - Global Ecol. Biogeogr.15: 8-20. Laurance, W. F. 2008. Theory meets reality: how habitat fragmentation research has transcended island biogeographic theory. - Biol. Conserv. 141: 1731-1744.

Legrand, D. et al. In press. Eco-evolutionary dynamics in fragmented landscapes. Ecography. 
Leroux, S. J. et al. 2007. Accounting for system dynamics in reserve design. - Ecol. Appl.

17: $\quad 1954-1966$.

Leroux, S. J. et al. In press. Structural uncertainty in models projecting the consequences of habitat loss and fragmentation on biodiversity. Ecography.

Lindenmayer, D. B. and Fischer, J. 2007. Tackling the habitat fragmentation panchrestron.

- $\quad$ Trends Ecol. Evol. 22: 127-132.

Lindenmayer, D. B. et al. 2007. The need for pluralism in landscape models: a reply to

Dunn and Majer. - Oikos 116: 1419-1421.

Lyet, A. et al. 2013. Fine-scale regional distribution modelling of rare and threatened species: $\quad$ bridging GIS Tools and conservation in practice. - Divers. Distrib. 19: 651663.

MacArthur, R. H. and Wilson E. O. 1967. The Theory of Island Biogeography. - Princeton University Press.

Margules, C. R. 1993. The Wog Wog habitat fragmentation experiment. - Environ.

Conserv. 19: $316-325$.

McCune, J. L. In press. Species distribution models predict rare species occurrences despite significant effects of landscape context. - J. Appl. Ecol.

McIntyre, S. and Hobbs, R. J.. 1999. A framework for conceptualizing human effects on landscapes and its relevance to management and research models. - Conserv. Biol.

13: $\quad 1282-1292$.

Mendenhall, C. D. et al. 2014. Predicting biodiversity change and averting collapse in agricultural landscapes. - Nature 509: 213-217. 
Mesquita, R. C. G, et al. 2001. Alternative successional pathways in the Amazon Basin. - J.

Ecol. 89: 528-537.

Mitchell, M. G. E. et al. 2014. Forest fragments modulate the provision of multiple ecosystem services. - J. Appl. Ecol. 51: 909-918.

Mittermeier, R. A. et al. 2003. Wilderness and biodiversity conservation. - P. Natl. Acad.

Sci. USA. 100: 10309-10313.

Newbold, T. et al. 2015. Global effects of land use on local terrestrial biodiversity. - Nature 520: $45-50$.

Noss, R. F. and Cooperrider, A. 1994. Saving nature's legacy: protecting and restoring biodiversity. - Island Press.

Pardini, R. et al. 2010. Beyond the fragmentation threshold hypothesis: regime shifts in biodiversity across fragmented landscapes. - PLoS One 5: e13666.

Pfeifer, M., et al. 2014. BIOFRAG - a new database for analyzing BIOdiversity responses to forest FRAGmentation. - Ecology and Evolution 4: 1524-1537.

Price, B. et al. 2009. Continuum or discrete patch landscape models for savanna birds?

Toward a pluralistic approach. - Ecography 32: 745-756.

Rand, T. A. et al. 2006. Spillover edge effects: the dispersal of agriculturally subsedized insect natural enemies into adjacent natural habitats. - Ecol. Let. 9: 603-614.

Scheller, R. M. et al. 2007. Design, development, and application of LANDIS-II, a spatial landscape simulation model with flexible temporal and spatial resolution. - Ecol.

Model. $\quad$ 201: 409-419.

Schmiegelow, F.K. and Mönkkönen, M. 2002. Habitat loss and fragmentation in dynamic landscapes: avian perspectives from the boreal forest. - Ecol. Appl. 12: 375-389. 
Shafer, C. L. 1990. Nature reserves: island theory and conservation practice. - Smithsonian Institute Press.

Terborgh, J. et al. 2001. Ecological meltdown in predator-free forest fragments. - Science 294: $1923-1926$.

Umetsu, F. et al. 2008. Importance of estimating matrix quality for modeling species

distribution in complex tropical landscapes: a test with Atlantic forest small mammals. Ecography 31: 359-370.

Vitousek, P. M. et al. 1997. Human domination of Earth's ecosystem. - Science 277: 494499. 


\section{Table Legends}

Table 1. A proposed decision-making framework for the application of patch-matrix, continuum, and hybrid models in the study of the effects of landscape change. The framework focuses on study objectives and attributes of the system under study (landscape attributes, and when individual species are the focus, characteristics of the species). In instances when all considerations are in agreement with either patch-matrix or continuum model, the respective model is recommended; instances with mixed agreement suggest a hybrid model. Data requirements for patch-matrix and continuum models are then listed; hybrid models require components of both sets of data.

\begin{tabular}{|c|c|c|}
\hline & Patch-matrix model preferred: & Continuum model preferred: \\
\hline \multicolumn{3}{|l|}{ Study objective } \\
\hline & $\begin{array}{l}\text { Questions focused on: } \\
\text { - A particular habitat type } \\
\text { - Multiple species that appear to } \\
\text { respond similarly to land use or } \\
\text { land cover type } \\
\text { - An entire community }\end{array}$ & $\begin{array}{l}\text { Questions focused on: } \\
\text { - A suite of habitat types } \\
\text { - Multiple species that appear to } \\
\text { respond differently to land use or } \\
\text { land cover type } \\
\text { - Individuals of one species } \\
\text { - A single population }\end{array}$ \\
\hline & $\begin{array}{l}\text { To understand species associations } \\
\text { with land cover types (forest, } \\
\text { grassland, etc.) }\end{array}$ & $\begin{array}{l}\text { To understand species } \\
\text { associations with various biotic } \\
\text { and abiotic gradients }\end{array}$ \\
\hline \multicolumn{3}{|l|}{$\begin{array}{l}\text { Attributes of landscape under } \\
\text { consideration }\end{array}$} \\
\hline & $\begin{array}{l}\text { Landscapes, with two or few land } \\
\text { cover types }\end{array}$ & $\begin{array}{l}\text { Landscapes, with many land } \\
\text { cover types }\end{array}$ \\
\hline
\end{tabular}

'This article is protected by copyright. All rights reserved.' 


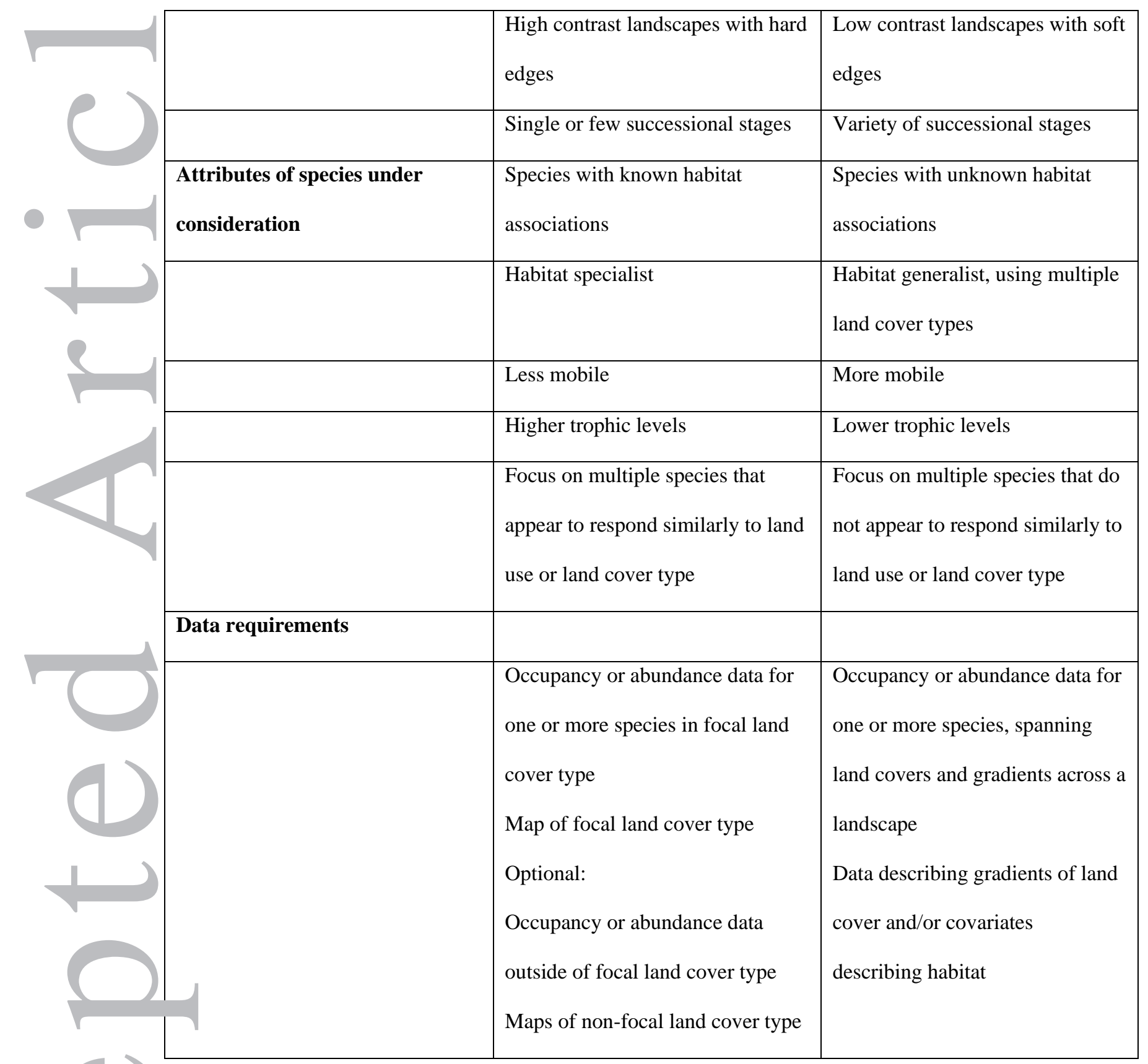

'This article is protected by copyright. All rights reserved.' 
Table 2. Predictions and support for patch-matrix, continuum, or hybrid models for beetle species in the Hope River Forest The Predictions

Fragm ntation Project (HRFFP) and Wog Wog habitat fragmentation experiment. We considered models within four AICc points of the top model as having support; in some cases, multiple models were supported for a single species. See Appendices A and $\mathrm{B}$. nomnlete model results.

\begin{tabular}{|c|c|c|c|c|c|c|}
\hline & Land cover types & $\begin{array}{l}\text { Landscape } \\
\text { contrast }\end{array}$ & $\begin{array}{l}\text { Edge } \\
\text { structure }\end{array}$ & Species & $\begin{array}{l}\text { Model predicted } \\
\text { by framework }\end{array}$ & Supported model(s) \\
\hline \multirow[t]{7}{*}{ HRFFP } & ru.st, grassland & Strong & Hard & & & \\
\hline & & & & Forest-specialist carnivore & Patch-matrix & Hybrid \\
\hline & & & & Grassland-specialist carnivore & Patch-matrix & Hybrid \\
\hline & & & & Habitat generalist carnivore & Hybrid & Hybrid; continuum \\
\hline & & & & Generalist herbivore & Hybrid & Hybrid \\
\hline & & & & Forest-specialist herbivore & Hybrid & Hybrid \\
\hline & & & & Grassland specialist herbivore & Hybrid & Hybrid \\
\hline \multirow{2}{*}{$\begin{array}{l}\text { Wog } \\
\text { Wog }\end{array}$} & For st, plantation & Weak & Soft & & & \\
\hline & & & & Forest-specialist carnivore & Hybrid & Hybrid, continuum \\
\hline
\end{tabular}




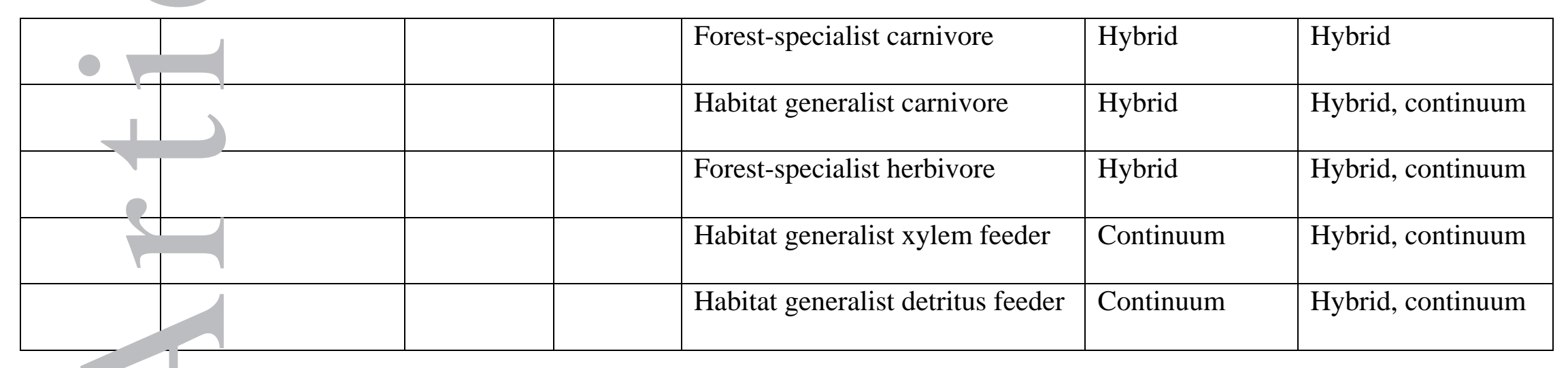

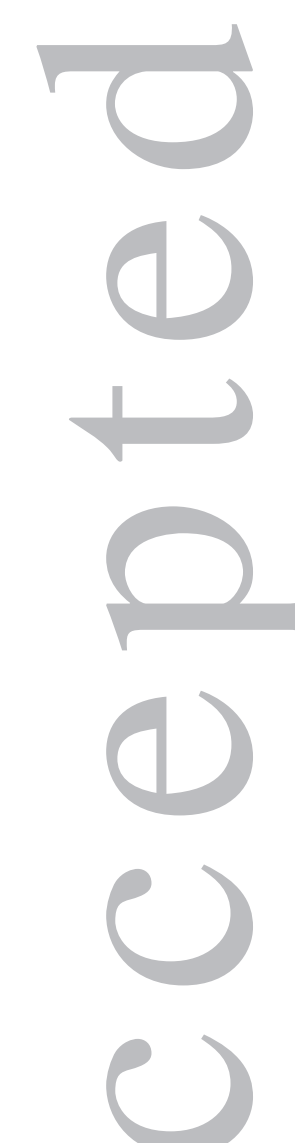

'This article is protected by copyright. All rights reserved.' 


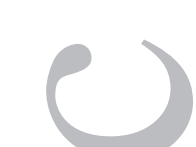

\section{Figure Legends}

Figure 1 . Terre rial landscapes range from relatively intact (left two panels) to highly modified (right two panels) and in their degree of heterogeneity, and landscape contrast. Upper left - intact Brazilian tropical lowland forest (photo: David Minor).

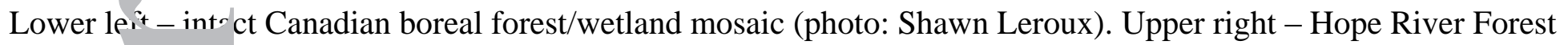

Fragmentation Project: fragmented New Zealand southern beech forest/anthropogenic grassland mosaic with strong landscape cor at anc lard structural edges (photo: Robert Ewers). Lower right - Wog Wog Habitat Fragmentation Experiment:

fragmented An ralian Eucalyptus forest/pine plantation mosaic with weak landscape contrast and soft structural edges (photo:

\section{Kendi Davies).}

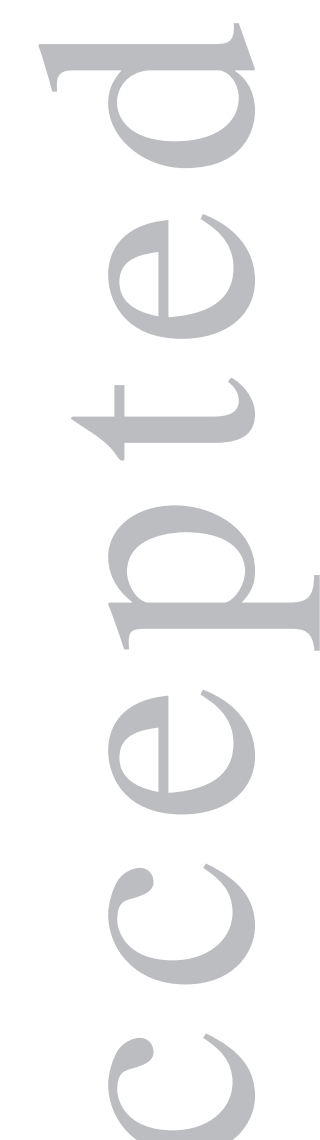

'This article is protected by copyright. All rights reserved.' 

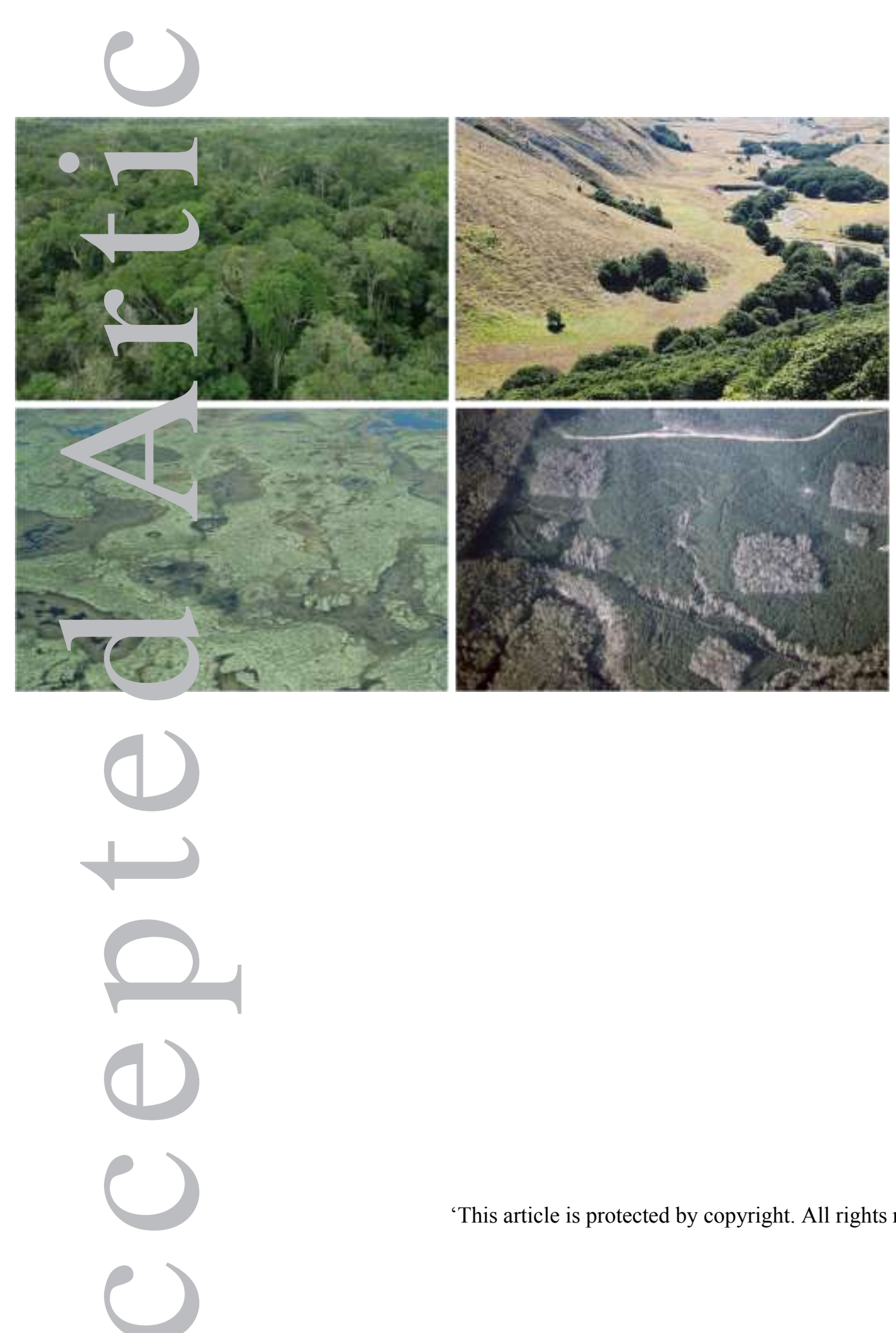


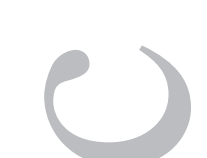

Figure 2. Proposed before-after-control-impact experimental test of patch-matrix, continuum, and hybrid models. One or more landsc pes is se npled for species abundances and environmental variables describing habitat (black dots) along environmental gradients (one of many represented by contour lines) before and after experimental fragmentation (top two panels) and over the course - mannvary (bottom panel). Intact, destroyed, and recovering habitat is represented with shades of gray (dark to light, respectively). Within each landscape, unfragmented control areas are retained (dark gray in middle and lower panel). Note the mo sepl ation for purposes of illustration.

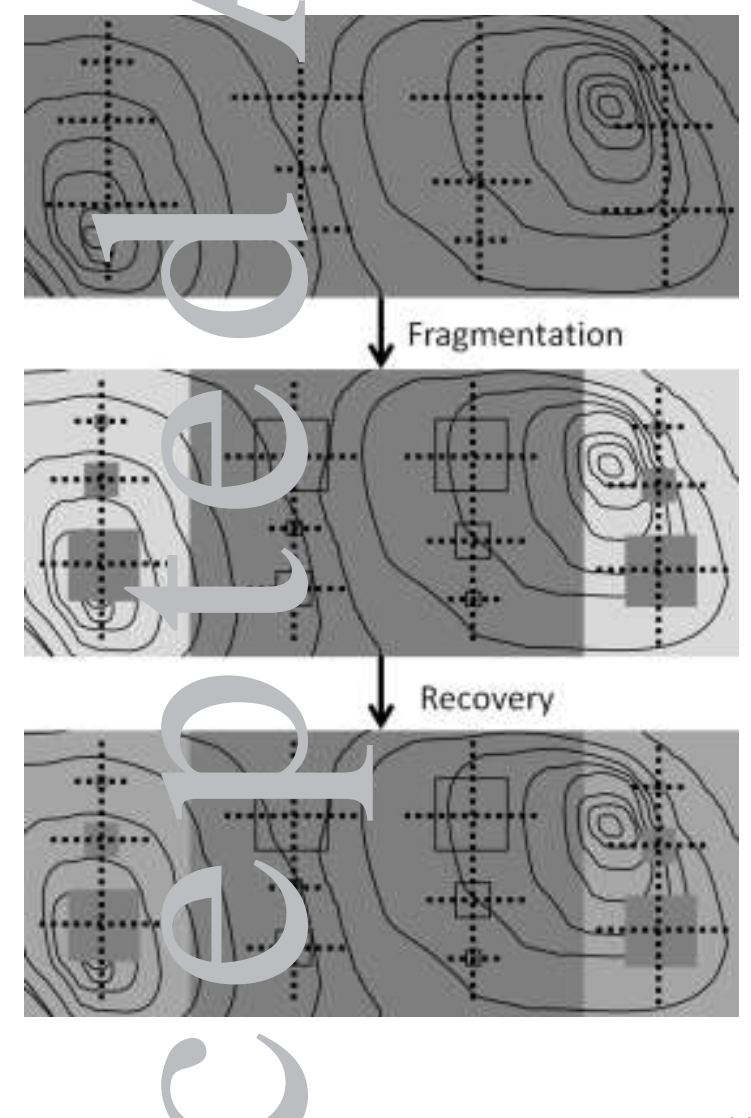

'This article is protected by copyright. All rights reserved.' 